\title{
Anti-Müllerian hormone and letrozole levels in boys with constitutional delay of growth and puberty treated with letrozole or testosterone
}

\author{
Kohva, E.
}

2020-02

Kohva, E, Varimo , T , Huopio , H, Tenhola , S, Voutilainen , R , Toppari , J , Miettinen , P J , Vaaralahti , K , Viinamäki , J , Backman , J T , Hero , M \& Raivio , T 2020 , '

Anti-Müllerian hormone and letrozole levels in boys with constitutional delay of growth and puberty treated with letrozole or testosterone ' , Human Reproduction, vol. 35 , no. 2 , pp. 257-264 . https://doi.org/10.1093/humrep/dez231

http://hdl.handle.net/10138/314417

https://doi.org/10.1093/humrep/dez231

cc_by_nc

publishedVersion

Downloaded from Helda, University of Helsinki institutional repository.

This is an electronic reprint of the original article.

This reprint may differ from the original in pagination and typographic detail.

Please cite the original version. 


\title{
Anti-Müllerian hormone and letrozole levels in boys with constitutional delay of growth and puberty treated with letrozole or testosterone
}

\author{
E. Kohva', T. Varimo', H. Huopio², S. Tenhola ${ }^{3}$, R. Voutilainen ${ }^{2}$, \\ J. Toppari', P.J. Miettinen', K. Vaaralahti' , J. Viinamäki ${ }^{5}$, J.T. Backman ${ }^{5}$, \\ M. Hero', and T. Raivio ${ }^{1,6, *}$
}

\begin{abstract}
'Children's Hospital, Pediatric Research Center, Helsinki University Hospital, Helsinki, Finland ${ }^{2}$ Department of Pediatrics, Kuopio University Hospital, University of Eastern Finland, Kuopio, Finland ${ }^{3}$ Department of Pediatrics, Kymenlaakso Central Hospital, Kotka, Finland ${ }^{4}$ Department of Pediatrics, Turku University Hospital and Institute of Biomedicine, Research Centre for Integrated Physiology and Pharmacology, University of Turku, Turku, Finland ${ }^{5}$ Department of Clinical Pharmacology, and Individualized Drug Therapy Research Program, Faculty of Medicine, University of Helsinki, Helsinki, Finland ${ }^{6}$ Translational Stem Cell Biology and Metabolism Research Program, Faculty of Medicine, University of Helsinki, Helsinki, Finland
\end{abstract}

*Correspondence address. University of Helsinki, Faculty of Medicine, Medicum/Physiology, P.O. Box 63 (Haartmaninkatu 28 8), FI-000I4 University of Helsinki, Helsinki, Finland. Email: taneli.raivio@helsinki.fi

Submitted on July 9, 2019; resubmitted on September 15, 2019; editorial decision on September 29, 2019

\begin{abstract}
STUDY QUESTION: Does treatment of constitutional delay of growth and puberty (CDGP) in boys with aromatase inhibitor letrozole (Lz) or conventional low-dose testosterone $(\mathrm{T})$ have differing effects on developing seminiferous epithelium?
\end{abstract}

SUMMARY ANSWER: Anti-Müllerian hormone (AMH) declined similarly in both treatment groups, and the two Sertoli cell-derived markers $(\mathrm{AMH}$ and inhibin $\mathrm{B}(\mathrm{B} B)$ ) exhibited differing responses to changes in gonadotrophin milieu.

WHAT IS KNOWN ALREADY: Boys with CDGP may benefit from puberty-inducing medication. Peroral Lz activates gonadotrophin secretion, whereas intramuscular low-dose $T$ may transiently suppress gonadotrophins and $\mathrm{B}$.

STUDY DESIGN, SIZE, DURATION: Sera of 28 boys with CDGP who participated in a randomised, controlled, open-label trial at four paediatric centres in Finland between August 2013 and January 2017 were analysed. The patients were randomly assigned to receive either $\mathrm{Lz}$ ( $2.5 \mathrm{mg} /$ day) $(n=15)$ or $\mathrm{T}(\mathrm{I} \mathrm{mg} / \mathrm{kg} /$ month) $(n=13)$ for 6 months.

PARTICIPANTS/MATERIALS, SETTING, METHODS: The 28 patients were at least 14 years of age, showed first signs of puberty, wanted medical attention for CDGP and were evaluated at 0, 3, 6 and 12 months of visits. AMH levels were measured with an electrochemiluminescence immunoassay and Lz levels with liquid chromatography coupled with tandem mass spectrometry.

MAIN RESULTS AND THE ROLE OF CHANCE: AMH levels decreased in both treatment groups during the I2-month follow-up $(P<0.000 \mathrm{I})$. Between 0 and 3 months, the changes in gonadotrophin levels (increase in the $\mathrm{Lz}$ group, decrease in the T group) correlated strongly with the changes in levels of iB (FSH vs iB, $r=0.55, P=0.002$; $\mathrm{LH}$ vs iB, $r=0.72, P<0.000 \mathrm{I}$ ), but not with the changes in AMH $(P=$ NS). At 12 months, AMH levels did not differ between the groups $(P=N S)$. Serum Lz levels (range, 124-1262 nmol/L) were largely explained by the $L z$ dose per weight (at 3 months $r=0.62, P=0.01$; at 6 months $r=0.52, P=0.05$ ). Lz levels did not associate with changes in indices of hypothalamic-pituitary-gonadal axis activity or Sertoli cell markers (in all, $P=N S$ ).

LIMITATIONS, REASONS FOR CAUTION: The original trial was not blinded for practical reasons and included a limited number of participants.

WIDER IMPLICATIONS OF THE FINDINGS: In early puberty, treatment-induced gonadotrophin stimulus was unable to counteract the androgen-mediated decrease in $\mathrm{AMH}$, while changes in $\mathrm{B}$ levels were associated with changes in gonadotrophin levels. AMH decreased similarly in both groups during the treatment, reassuring safety of developing seminiferous epithelium in both treatment approaches. Since a fixed dose of Lz induced variable serum Lz levels with a desired puberty-promoting effect in all boys, more research is needed to aim at a minimal efficient dose per weight.

(C) The Author(s) 2020. Published by Oxford University Press on behalf of the European Society of Human Reproduction and Embryology.

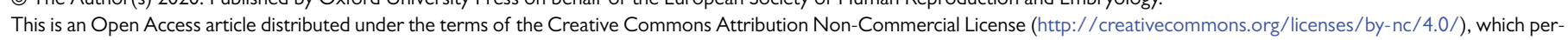

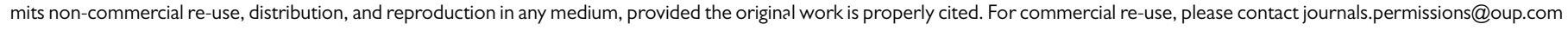


STUDY FUNDING/COMPETING INTEREST(S): This study was supported by the Academy of Finland, the Foundation for Pediatric Research, the Emil Aaltonen Foundation, Sigrid Juselius Foundation and Helsinki University Hospital Research Funds. The authors have nothing to disclose.

TRIAL REGISTRATION NUMBER: NCT0I7977I8

Key words: constitutional delay of growth and puberty / anti-Müllerian hormone / inhibin B / letrozole / testosterone

\section{Introduction}

Constitutional delay of growth and puberty (CDGP) is the most common reason for delayed puberty in both sexes. The condition is self-limited but can cause significant psychosocial distress and complicate interaction with peers. Accordingly, reassurance and watchful waiting are usually sufficient approaches to treatment (Palmert and Dunkel, 20I2). On the other hand, low-dose androgen treatment has been used for decades for boys who warrant medical intervention for their condition (Soliman et al., 1995; Crowne et al., 1997). The treatment schedules are quite variable, and the efficacy of the treatment is clearly an under-investigated area in adolescent medicine with very few randomised trials available (Rosenfeld et al., 1982; Soliman et al., 1995; Crowne et al., 1997).

We have recently described a new treatment approach for boys with CDGP: a 6-month regimen of peroral aromatase inhibitor letrozole (Lz) $(2.5 \mathrm{mg} /$ day), which is more efficacious in inducing hypothalamicpituitary-gonadal (HPG) axis activity and testis growth than the lowdose testosterone (T) treatment (Varimo et al., 20l9). Lz, which accelerated height growth, may thus provide a new peroral treatment option for boys with CDGP. When we compared Lz with the traditional low-dose T treatment, we found that inhibin B (iB), a marker of Sertoli cell and seminiferous epithelium function, declined in response to lowdose $\mathrm{T}$, whereas it increased in Lz-treated boys. At the time of our original report, it was unclear whether this reflected Sertoli cell proliferation, a phenomenon of early puberty (Cortes et al., 1987; Sharpe et al., 2003), or merely a response to altered gonadotrophin levels. Indeed, iB has been suggested to be at least partially gonadotrophindependent in early puberty (Grinspon et al., 2013). Another intriguing finding was that the Lz-treated boys had larger testes 6 months after the treatment than those who received low-dose $\mathrm{T}$, although the iB levels did not differ at that time point (Varimo et al., 2019). To better understand the putative effects of $L z$ and low-dose $T$ on the developing seminiferous epithelium, we now report serum levels of anti-Müllerian hormone (AMH), which is another Sertoli cell product and a suggested surrogate marker for Sertoli cell number and function (Grinspon et al., 20I8). It is known that FSH stimulates AMH secretion in prepuberty (Lukas-Croisier et al., 2003; Young et al., 2005), and that the paracrine action of T suppresses AMH levels in early puberty (Rey, 1998). However, the concomitant changes in $\mathrm{B}$ and $\mathrm{AMH}$ levels in boys receiving Lz or low-dose $T$ have not been described.

Although aromatase inhibitors have been employed in paediatric studies aimed to increase adult height (Wickman et al., 200 I; Hero et al., 2005; Mauras et al., 2008; Mauras et al., 2016; Leschek et al., 2017), and in treating rare conditions causing estrogen excess (Wit et al., 20 I I), there are no reports on circulating Lz levels in paediatric patients. The randomised, controlled studies from our centres have employed a fixed daily dose of $2.5 \mathrm{mg}$ (Hero et al., 2005; Varimo et al., 2019), same as that used in adults, and it might be possible to achieve the desired treatment effects (i.e. HPG axis activation) with a smaller dose as well. To elucidate this question, we report the circulating Lz levels in CDGP patients (Varimo et al., 2019) and correlate them to clinical and biochemical markers of puberty with special attention to the serum $\mathrm{AMH}$ and $\mathrm{iB}$ levels.

\section{Materials and Methods}

Thirty boys with CDGP were recruited to a randomised controlled trial, which compared 6-month aromatase inhibitor Lz treatment (2.5 mg/day, Letrozol Accord 2.5 mg; Accord Healthcare B.V., Utrecht, Netherlands) to low-dose intramuscular $T$ treatment (I mg/kg/month, Sustanon 250; Aspen Nordic, Ballerup, Denmark) (Varimo et al., 2019). The study protocol is illustrated in Supplementary Figure SI and the distributions of hormonal and clinical markers of puberty during the study period in Supplementary Table SI. In brief, the boys were carefully examined, and those with other causes than CDGP for delayed puberty were excluded. The inclusion criteria were testicular volume between 2.5 and $4 \mathrm{ml}$ and serum $T<5 \mathrm{nmol} / \mathrm{L}$ or serum $T \geq 1 \mathrm{nmol} / \mathrm{L}$, if the mean testicular volume was $<2.5 \mathrm{ml}$, or Tanner genital stage 2 and serum $T<3$ nmol/L (Varimo et al., 2019). At the start of the trial, the boys were above 14 years of age (mean 14.7 years $95 \% \mathrm{Cl} 14.4$ to 14.9 years) and had a mean testicular volume of $3.1 \mathrm{ml}(95 \% \mathrm{Cl} 2.8-3.5 \mathrm{ml})$ and a mean serum $\mathrm{T}$ concentration of $2.1 \mathrm{nmol} / \mathrm{L}(95 \% \mathrm{Cl} 1.6-2.5 \mathrm{nmol} / \mathrm{L})$. During the study period, all boys progressed in puberty. At the study visits at 0,3 , 6 and 12 months, morning blood samples were drawn and sera stored at $-80^{\circ} \mathrm{C}$. In the $\mathrm{T}$ group, the 3 - and 6-month samples represented the peak and trough concentrations of exogenous $T$ (the 3 -month visit was scheduled I week after the fourth injection and the 6-month visit 4 weeks after the last injection). At the start of the study, four boys in the Lz group and three boys in the $T$ group were at Tanner genital stage I, whereas at the 12-month visit all boys had progressed into puberty. Two participants in the T group were excluded: one because of a protocol deviation, and the other due to missing samples. Data were thus available for 15 boys treated with $L z$ and 13 boys treated with T.

The levels of gonadotrophins, $\mathrm{T}$, estradiol and $\mathrm{iB}$ were determined with routine laboratory techniques (immunoelectrochemiluminometric, liquid chromatography/mass spectrometric and enzyme-linked immunosorbent assays), as described before (Varimo et al., 2019). $\mathrm{GnRH}$-stimulation test was performed by injecting $\mathrm{GnRH}$ analogue (3.5 $\mathrm{\mu g} / \mathrm{kg}$, Relefact ${ }^{\circledR} \mathrm{LH}-\mathrm{RH} 0.1 \mathrm{mg}$; Aventis Pharma, Frankfurt, Germany) intravenously as a single bolus, and serum gonadotrophin concentrations were measured for up to $90 \mathrm{~min}$.

Lz concentrations were determined at 3 and 6 months of the study by using a Shimadzu Nexera Liquid Chromatography System (Shimadzu Corporation, Kyoto, Japan) coupled to an API 3000 tandem mass 
Table I Correlations between baseline serum AMH level and baseline clinical and hormonal markers of puberty.

\begin{tabular}{|c|c|c|c|c|c|c|c|c|c|}
\hline & & $\begin{array}{c}\text { Testosterone } \\
\text { (nmol/L) }\end{array}$ & $\begin{array}{l}\text { Estradiol } \\
\text { (pmol/L) }\end{array}$ & $\begin{array}{c}\text { Inhibin B } \\
\text { (ng/L) }\end{array}$ & LH (IU/L) & $\begin{array}{c}\text { FSH } \\
\text { (IU/L) }\end{array}$ & $\begin{array}{l}\text { LH * } \\
\text { (IU/L) }\end{array}$ & $\begin{array}{l}\text { FSH * } \\
\text { (IU/L) }\end{array}$ & $\begin{array}{c}\text { Testicular } \\
\text { volume }(\mathbf{m l})\end{array}$ \\
\hline \multirow[t]{2}{*}{$\mathrm{AMH}(\mu \mathrm{g} / \mathrm{L})$} & $\begin{array}{l}\text { Spearman } \\
\text { correlation }\end{array}$ & -0.36 & -0.35 & 0.39 & -0.24 & -0.49 & -0.39 & -0.53 & -0.26 \\
\hline & $P$ value & 0.06 & 0.07 & 0.04 & 0.23 & 0.009 & 0.04 & 0.005 & 0.18 \\
\hline
\end{tabular}

AMH, anti-Müllerian hormone

* Maximal stimulated value in $\mathrm{GnRH}$ test

spectrometer (AB Sciex, Toronto, Ontario, Canada). The lower limit of quantification in plasma was $0.5 \mathrm{ng} / \mathrm{ml}(1.75 \mathrm{nmol} / \mathrm{L})$, and the upper limit of quantification was $500 \mathrm{ng} / \mathrm{ml}$ ( $1752 \mathrm{nmol} / \mathrm{L})$. Serum AMH determinations were performed with the electrochemiluminescence immunoassay Elecsys ${ }^{\circledR}$ AMH (Modular Analytics el70, Roche diagnostics, Mannheim, Germany). The detection limit of the assay was $0.07 \mathrm{pmol} / \mathrm{L}$, and inter-assay CV $2.6 \%$ at concentration of I $\mu \mathrm{g} / \mathrm{L}$.

Written informed consents from all participants and their guardians were obtained. The study was approved by the Finnish National Committee on Medical Research Ethics (TUKIJA) and the Finnish Medicines Agency (FIMEA). The principles of Good Clinical Practice and the declaration of Helsinki were applied. The study protocol was registered to ClinicalTrials.gov (registration number NCT0 I7977।8).

\section{Statistical analyses}

The data are presented as the mean and the $95 \%$ confidence intervals $(\mathrm{Cl})$, unless otherwise stated in the text. Statistical analyses were performed with SPSS statistical software for Windows, version 22.0 (SPSS, Chicago, IL, USA).

At baseline, correlations between serum $\mathrm{AMH}$ concentration and clinical and hormonal markers of puberty (serum T, estradiol, iB, LH and FSH concentrations; GnRH-stimulated $\mathrm{LH}$ and FSH; and testicular volume) were analysed with Spearman rank correlation. Differences between the Lz- and T-treatment groups in changes of AMH levels over the 12-month study period were analysed with mixed repeated measures ANOVA, with treatment as the between-subjects factor and time (baseline, 3-month, 6-month and 12-month visits) as the within-subjects factor. As assumption of sphericity was violated, tests of significance were adjusted with Greenhouse-Geisser correction. Within-group changes in $\mathrm{AMH}$ levels were analysed with repeated measures ANOVA, and Bonferroni correction was used for withingroup pairwise analyses. In addition, we evaluated the changes in $\mathrm{AMH}$ levels within the first 6 months (i.e. during the treatment) in the two treatment groups by repeated measures ANOVA, within subject analyses adjusted with Greenhouse-Geisser correction, and further compared the AMH change between the groups with one-way repeated measures analysis of covariance (ANCOVA) controlling for the effect of baseline $\mathrm{AMH}$.

In order to evaluate the connection between Sertoli cell-secreted peptides with gonadotrophins, we calculated Pearson correlations between changes ( $0-3$ months) in $\mathrm{AMH}$ and iB levels and changes $(0$ 3 months) in $\mathrm{FSH}$ and $\mathrm{LH}$ levels. To further evaluate the change in $\mathrm{AMH}$, we constructed a linear regression model explaining change in $\mathrm{AMH}$ ( $0-3$ months) with the corresponding changes in $\mathrm{T}$ and FSH levels.
At 3 and 6 months, correlations between serum Lz concentrations and Lz doses by weight $(\mathrm{mg} / \mathrm{kg}$ ) were assessed with Pearson correlation. Correlations between Lz concentrations at 3 and 6 months and changes in clinical and hormonal markers of puberty between baseline and 3 or 6 months (serum T, estradiol, iB, LH, FSH and AMH concentrations; $T$ /estradiol ratio and testis volume) were assessed with Spearman rank correlation. The correlation of number of patient-reported side effects and Lz concentrations at 3 and 6 months was calculated with Spearman rank correlation test. All $P$ values were two-sided, and $P$ values $<0.05$ were selected to indicate statistical significance.

\section{Results}

We investigated circulating AMH levels in boys with CDGP who had been treated either with traditional low-dose $\mathrm{T}$ or peroral aromatase inhibitor Lz. Correlations between serum AMH levels and clinical and hormonal markers of puberty at the start of the study are shown in Table I. In particular, AMH levels correlated negatively with $\mathrm{FSH}$ and $\mathrm{GnRH}$-stimulated $\mathrm{FSH}$ and $\mathrm{LH}$ levels and positively with iB levels (Table I). We next investigated longitudinal changes in $\mathrm{AMH}$ levels between the treatment groups during the 12-month study period. Overall, the decrease in AMH level over time was significant $(P<0.000 \mathrm{I})$. There were no clear differences in $\mathrm{AMH}$ levels between the study groups during the period of 6 months of medical intervention and 6 months of follow-up ( $P=\mathrm{NS}$ ) (Fig. I). Between baseline and 12 months, AMH declined from $42.2 \mu \mathrm{g} / \mathrm{L}(95 \% \mathrm{Cl} 26 . \mathrm{I}-58 . \mathrm{I})$ to $15.1 \mathrm{\mu g} / \mathrm{L}(95 \% \mathrm{Cl} 8.9-21.2)(P=0.003)$ in the $\mathrm{Lz}$ group and from $35.8 \mu \mathrm{g} / \mathrm{L}(95 \% \mathrm{Cl} 20.9-50.8)$ to $13.8 \mu \mathrm{g} / \mathrm{L}(95 \% \mathrm{Cl} 7.5-20.2)$ in the T group $(P=0.002)$. The change was similar in both treatment groups $(P=N S)$.

When the analyses were restricted to the first 6 months (i.e. during treatment), the change in $\mathrm{AMH}$ differed in the two treatment groups $(P=0.05)$ : serum AMH decreased from $42.2 \mu \mathrm{g} / \mathrm{L}(95 \% \mathrm{Cl} 26 . \mathrm{I}-58.2)$ to $24.9 \mu \mathrm{g} / \mathrm{L}(95 \% \mathrm{Cl} 13.0-36.7)(P=0.00 \mathrm{I})$ in the $\mathrm{Lz}$ group and from $35.8 \mu \mathrm{g} / \mathrm{L}(95 \% \mathrm{Cl} 20.9-50.8)$ to $29.2 \mu \mathrm{g} / \mathrm{L}(95 \% \mathrm{Cl}$ 14.6-43.4) $(P=0.05 \mathrm{I})$ in the T group. Individual AMH levels of the boys in the two treatment groups are shown in Fig. 2. When the baseline AMH levels were used to adjust the decrease in $\mathrm{AMH}$ from baseline to 6 months, the difference was, however, no longer statistically significant $(P=N S)$.

Since it was evident that $\mathrm{AMH}$ exhibited a parallel change in both treatment groups (Fig. I), and that low-dose $\mathrm{T}$ suppressed gonadotrophins and iB at 3 months of the study (Varimo et al., 2019), we were keen to investigate the relationships between gonadotrophins and the serum Sertoli cell markers. The results of a regression model between baseline $\mathrm{AMH}$ and $\mathrm{T}$ and $\mathrm{FSH}$ levels are shown 


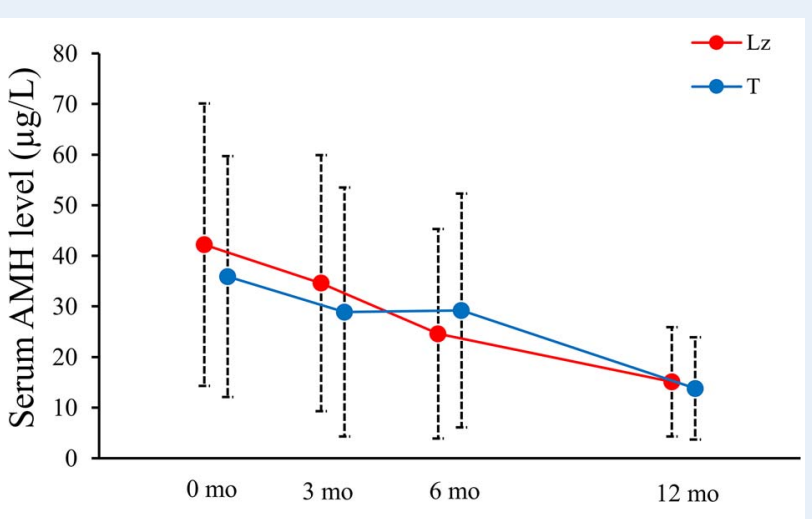

Figure I AMH in the two treatment groups. Serum AMH levels during 6 months of letrozole [Lz] (in red) or testosterone [T] (in blue) treatment and 6 months of follow-up in 28 boys with constitutional delay of growth and puberty (CDGP). The error bars indicate \pm SD. Mo, months; $\mathrm{AMH}$, anti-Müllerian hormone.

in Supplementary Table SII. Between 0 and 3 months of the study, the change in $\mathrm{AMH}$ levels did not correlate with the change in gonadotrophins (FSH $r=-0.06, P=0.77$; $\mathrm{LH} r=-0.06, P=0.75$ ). In contrast, the corresponding change in $\mathrm{iB}$ correlated strongly with the changes in gonadotrophins ( $\mathrm{FSH} r=0.55, P=0.002$; $\mathrm{LH} r=0.72$, $P<0.000 \mathrm{I}$ ) (Fig. 3). In a linear regression model explaining the change in $\mathrm{AMH}$ levels between 0 and 3 months with the corresponding changes in $\mathrm{T}$ and $\mathrm{FSH}$ levels, the results were non-significant in both treatment groups (Supplementary Table SIII).

We next investigated circulating Lz levels in the boys who were treated with it for 6 months. At 3 and 6 months of the treatment, mean serum Lz levels were $510 \mathrm{nmol} / \mathrm{I}(95 \% \mathrm{Cl}$ : 353-667 nmol/l) and $462 \mathrm{nmol} / \mathrm{I}(95 \% \mathrm{Cl}: 287-637 \mathrm{nmol} / \mathrm{l})$, respectively. Since all boys were treated with the same $\mathrm{Lz}$ dose $(2.5 \mathrm{mg} /$ day), the variability in serum Lz concentrations was largely explained by the daily Lz dose per weight $(\mathrm{mg} / \mathrm{kg})$ (Fig. 4). There was no clear relationship between serum Lz levels and markers of HPG axis activity, since Lz levels measured at 3 months did not correlate with the changes (0-3 months) in serum $\mathrm{T}$, estradiol, $\mathrm{T}$ /estradiol ratio, $\mathrm{iB}, \mathrm{LH}, \mathrm{FSH}$, or $\mathrm{AMH}$ levels or with the change in testicular volume (in all, $P=$ NS) (Supplementary Table SIV). At the end of treatment, Lz levels correlated with the change in testis volume (0-6 months $r=-0.52, P=0.05)$, but when adjusted with baseline testis volume, the correlation was no longer significant. At the same time, Lz levels did not correlate with the changes in hormonal markers of puberty (in all, $P=N S$ ) (Supplementary Table SIV). At the 3 or 6 months of visits, the number of reported adverse effects did not increase with higher Lz concentrations (data not shown, $P=N S)$.

\section{Discussion}

In this study, we showed that (i) AMH decreased similarly in both treatment groups, although Lz induced gonadotrophin secretion while low-dose T suppressed it; (ii) treatment-induced changes in circulating gonadotrophin levels were not associated with the changes in serum $\mathrm{AMH}$, while they correlated with changes in iB; and that (iii) varying
Lz-levels, largely explained by Lz dose per weight $(\mathrm{mg} / \mathrm{kg})$, were not associated to HPG-axis activity or patient-reported side effects.

Medications that are used to manipulate puberty should be wellinvestigated and safe without long-term adverse effects. This has not always been the case. For example, high-dose estrogen treatment, used to prevent tall stature in girls, was found to be associated with increased risk of infertility (Venn et al., 2004; Hendriks et al., 20 I2; Benyi et al., 20I4) and high-dose $T$ for the same indication in boys warrants careful consideration due to short-term side effects and subtle long-term increase in FSH levels, decrease in endogenous $\mathrm{T}$ levels and testis volume compared to untreated men (Hannema and Sävendahl, 2016; Albuquerque et al., 2017).

Puberty, the second postnatal activation period of the HPG axis, is associated in boys with Sertoli cell proliferation, which is essential for future fertility (Johnson et al., 1984; Cortes et al., 1987; Orth et al., 1988). Since men with a history of delayed puberty exhibit decreased sperm counts (Jensen et al., 2016), we deduced that it would be important to investigate circulating markers of seminiferous epithelium function in boys with delayed puberty during treatment with conventional low-dose $T$ or a potent third-generation aromatase inhibitor Lz.

During the course of treatment, serum AMH level decreased in both groups, suggesting that both exogenous low-dose $T$ and an increase in endogenous T levels are sufficient to down-regulate $\mathrm{AMH}$ secretion in early puberty. As AMH expression is considered to reflect maturation status of Sertoli cells (Sansone et al., 2019), our finding argues against unduly rapid maturation of Sertoli cell population in Lz-treated boys exposed to elevated gonadotrophin levels. Considering that Sertoli cell maturation is intimately related to their replicative capacity, our finding indirectly argues against untoward effect of Lz on future sperm producing capacity. Definitive data to support this view are scarce, as only one report exists on post-treatment sperm counts after aromatase inhibitor treatment during adolescence. In that study, limited number of growth hormone $(\mathrm{GH})$-deficient adolescents previously treated with anastrozole, another third-generation aromatase inhibitor, had similar sperm parameters as other $\mathrm{GH}$-deficient and $\mathrm{GH}$-sufficient adolescent controls (Mauras et al., 2005).

Despite the previously shown difference in gonadotrophin concentrations in the Lz- and T-treated groups (Varimo et al., 2019), we detected no evident difference between the groups in the $\mathrm{AMH}$ decline. These findings are in agreement with earlier reports showing a strong suppressing effect of T on AMH (Young et al., 1999; Young et al., 2003; Young et al., 2005). It is important to note that, in boys (Kohva et al., 2018) and men (Young et al., 2005) with gonadotrophin deficiency, recombinant $\mathrm{FSH}$ increases $\mathrm{AMH}$, whereas in healthy boys, this effect appears to be overcome by the pubertal increase in intratesticular T levels (Rey, 1998; Grinspon et al., 2013). Indeed, the expression of androgen receptors in Sertoli cells increases significantly at the age of 4 to 8 years (Chemes et al., 2008), and the pubertal decrease in AMH has been shown to be an early, androgen-dependent event (Hero et al., 20I2). Interestingly, the current study and our previous work (Hero et al., 20I2) both suggest that the pubertal decline in AMH occurs already as a consequence of low androgen levels, and that even very high intratesticular T levels achieved by Lz do not significantly accelerate this process. We have previously shown that, in boys with idiopathic short stature treated with Lz (Hero et al., 2005), AMH decline in early puberty did not differ from placebo group suggesting that Lz-induced 
$\mathrm{T}$ group

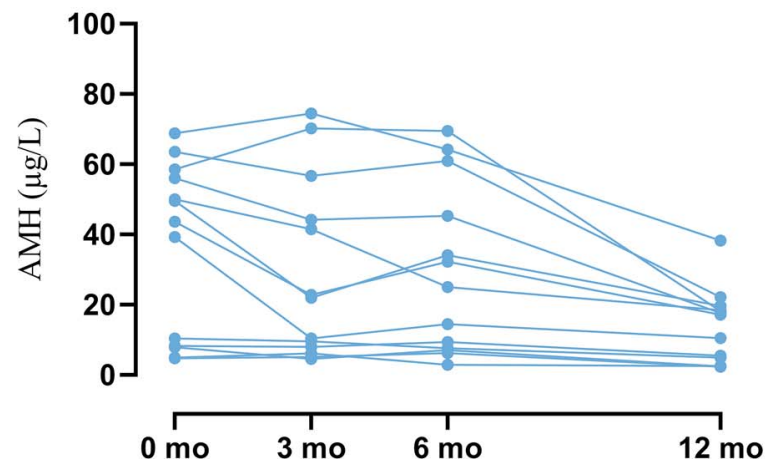

Lz group

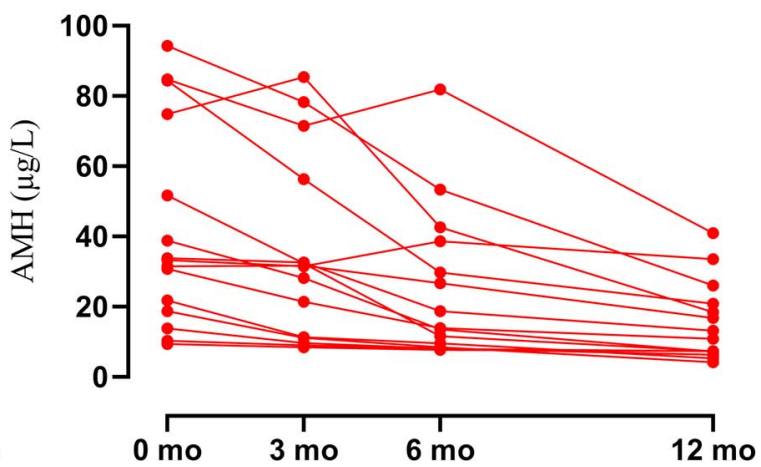

Figure 2 Individual AMH levels in CDGP boys during 6-month treatment. Boys treated with testosterone $[T]$ in blue $(n=13)$ and letrozole $[\mathrm{Lz}]$ in red $(n=15)$.
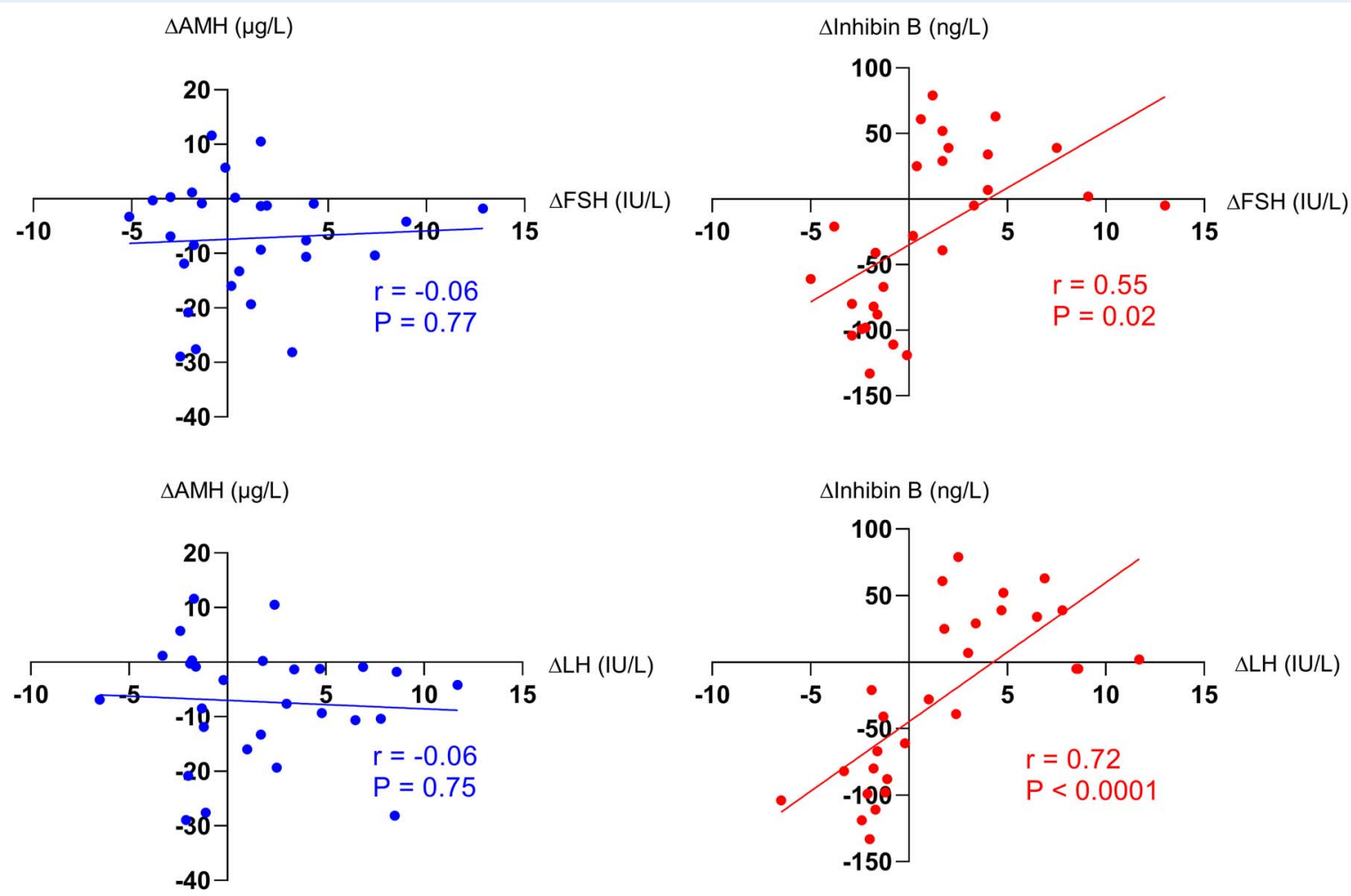

Figure 3 Correlation between gonadotrophins and Sertoli cell-secreted peptides. Correlations between changes in FSH and LH and changes in AMH (in blue) and inhibin B (in red) from baseline to 3-month-measurements in 28 boys with CDGP treated either with testosterone or letrozole.

strong gonadotrophin stimulus was unable to counteract the androgenmediated decrease in AMH (Hero et al., 20I2), and our current data on CDGP boys support this.

At the same time, the relationship between the treatment-induced changes in gonadotrophin and $\mathrm{iB}$ levels appeared quite the opposite as we were able to detect a positive correlation between them. Indeed, these results support the idea proposed by Grinspon et al. ithat serum iB level has two components in it: the gonadotrophin-dependent and the Sertoli cell mass-related components (Grinspon et al., 2013). Fur- thermore, a dual model has been proposed, in which immature Sertoli cells express both alpha- and beta-B inhibin subunits, whereas during puberty, the expression of beta-B-subunit is shifted from Sertoli cell to pachytene spermatocytes, early spermatid stages and to lesser extend Leydig cells (Andersson et al., 1998). This dependency of circulating iB on germ cells may explain why low-mid range iB levels associate with sperm counts and help to identify impaired spermatogenesis in men (Jørgensen et al., 20 I0). In contrast, AMH level does not appear as a useful hormonal marker of spermatogenesis (Aksglaede et al., 20।8). 
3 months of treatment

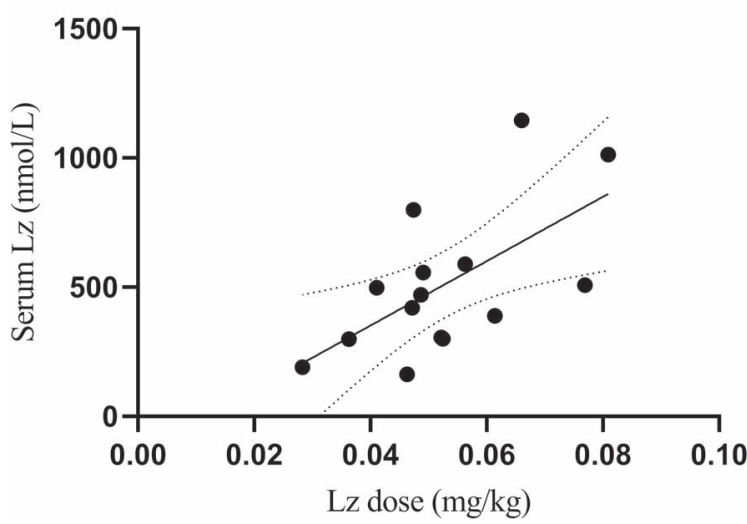

6 months of treatment

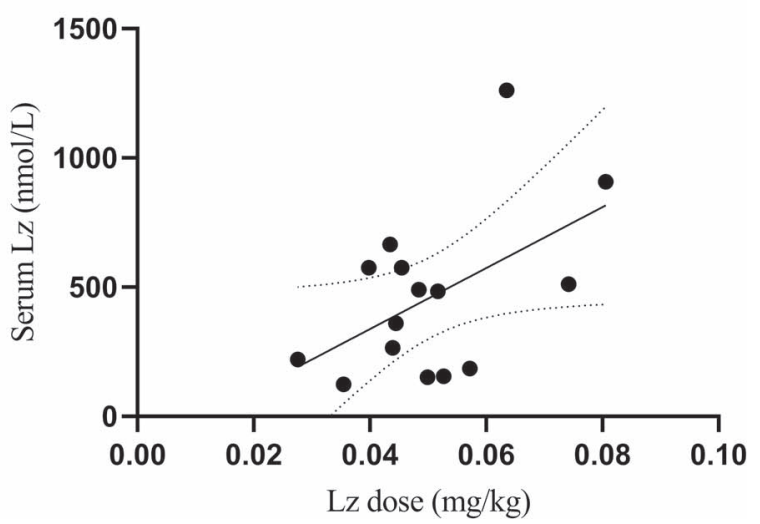

Figure 4 Relationship between letrozole (Lz) dose and serum Lz concentration. Correlations in serum Lz concentrations against Lz doses per weight in I 5 boys with constitutional delay of growth and puberty at $3(r=0.62, P=0.0 \mathrm{I})$ and 6 months $(r=0.52, P=0.05)$ of Lz treatment $(2.5 \mathrm{mg} /$ day). Solid line marks linear regression line and dotted lines $95 \%$ confidence intervals.

Given the reported lowered sperm counts in men with a history of delayed puberty (Jensen et al., 2016), it is tempting to hypothesise that Lz-induced activation of the HPG axis in early puberty will improve Sertoli cell proliferation and future spermatogenesis. Future studies are required to test this hypothesis.

To the best of our knowledge, this is the first study to report serum Lz concentrations in paediatric patients. The main determinant of circulating $L z$ levels was expectedly $L z$ dose per weight. Since the response to $L z$ treatment was heterogeneous, we could not identify an optimal HPG axis-inducing level of serum Lz. It is important to note that the current work was not powered to detect associations between Lz levels and HPG axis activity. On the other hand, it seems rational to aim at a minimal efficient dose per weight without losing the desired puberty-promoting effect. It is apparent that the current Lz dose was sufficient in all treated boys to induce the desired effect. Overall, the serum levels of Lz obtained with daily 2.5-mg dosing were similar to those observed in postmenopausal women (ranges 124-1262 nmol/L and 88-1227 nmol/L, when I $\mathrm{ng} / \mathrm{ml}$ equals $3.5 \mathrm{I} \mathrm{nmol} / \mathrm{L}$, respectively) (Desta et al., 20 I I). In postmenopausal women treated for breast cancer with a standard Lz dose of $2.5 \mathrm{mg}$ per day, the variation in plasma concentrations of $\mathrm{Lz}$ is largely explained by BMI, age and CYP2A6 genotype, and the therapeutic range of $\mathrm{Lz}$ is considered wide. Serum Lz level or CYP2A6 genotype have not been associated with arthralgia, a commonly reported adverse effect of Lz (Desta et al., 20 I I; Tanii et al., 20 I ; Borrie et al., 20l8), and in the current study, Lz was well-tolerated and high Lz levels were not associated with the patient-reported side effects.

In conclusion, we investigated serum AMH levels in boys with CDGP who had been treated with low-dose T or peroral aromatase inhibitor Lz. Reassuringly, AMH decreased similarly in both groups during the treatment. The treatment-induced changes in $\mathrm{AMH}$ levels were gonadotrophin-independent, while the change in $\mathrm{iB}$ correlated with the change in gonadotrophins. Circulating Lz levels were highly variable and the levels were not associated with the HPG axis activity in CDGP boys in early puberty. Thus, future studies are required to investigate if a Lz dose lower than $2.5 \mathrm{mg} /$ day is sufficient for the stimulation of the HPG-axis in boys with CDGP.

\section{Supplementary data}

Supplementary data are available at Human Reproduction online.

\section{Acknowledgements}

Annika Tarkkanen, MSs, is thanked for the skillful assistance.

\section{Authors' roles}

T.V., P.J.M., M.H. and T.R. designed the study concept. T.V., H.H., S.T., R.V., J.T., P.J.M., M.H. and T.R. contributed to participant enrolment. T.V., H.H., S.T., R.V., J.T., K.V., J.V. and J.T.B. acquired the data. E.K. and T.V. analysed the data and interpreted it together with P.J.M., J.T.B., M.H. and T.R. All authors contributed in drafting and revising the article and approved the final version to be published.

\section{Funding}

The Academy of Finland, The Foundation for Pediatric Research, The Emil Aaltonen Foundation, Sigrid Juselius Foundation, Helsinki University Hospital Research Funds.

\section{Conflict of interest}

The authors have nothing to disclose.

\section{References}

Aksglaede L, Olesen IA, Carlsen E, Petersen JH, Juul A, Jørgensen N. Serum concentration of anti-Müllerian hormone is not associated with semen quality. Andrology 20 18;6:286-292. 
Albuquerque EVA, Scalco RC, Jorge AAL. MANAGEMENT OF ENDOCRINE DISEASE: diagnostic and therapeutic approach of tall stature. Eur J Endocrinol 2017; I 76:R339-R353.

Andersson AM, Müller J, Skakkebaek NE. Different roles of prepubertal and postpubertal germ cells and Sertoli cells in the regulation of serum inhibin B levels. J Clin Endocrinol Metab 1998;83: 445I-4458.

Benyi E, Kieler H, Linder M, Ritzén M, Carlstedt-Duke J, Tuvemo T, Westphal O, Sävendahl L. Risks of malignant and non-malignant tumours in tall women treated with high-dose oestrogen during adolescence. Horm Res Paediatr 2014;82:89-96.

Borrie AE, Rose RV, Choi Y-H, Perera FE, Read N, Sexton T, Lock M, Vandenberg TA, Hahn K, Dinniwell R et al. Letrozole concentration is associated with CYP2A6 variation but not with arthralgia in patients with breast cancer. Breast Cancer Res Treat 20 I 8; I 72:37I-379.

Chemes HE, Rey RA, Nistal M, Regadera J, Musse M, GonzálezPeramato $P$, Serrano A. Physiological androgen insensitivity of the fetal, neonatal, and early infantile testis is explained by the ontogeny of the androgen receptor expression in Sertoli cells. J Clin Endocrinol Metab 2008;93:4408-44I2.

Cortes D, Müller J, Skakkebaek NE. Proliferation of Sertoli cells during development of the human testis assessed by stereological methods. Int J Androl 1987; 10:589-596.

Crowne EC, Wallace WH, Moore C, Mitchell R, Robertson WH, Holly JM, Shalet SM. Effect of low dose oxandrolone and testosterone treatment on the pituitary-testicular and $\mathrm{GH}$ axes in boys with constitutional delay of growth and puberty. Clin Endocrinol (Oxf) 1997;46:209-216.

Desta Z, Kreutz Y, Nguyen AT, Li L, Skaar T, Kamdem LK, Henry NL, Hayes DF, Storniolo AM, Stearns $V$ et al. Plasma letrozole concentrations in postmenopausal women with breast cancer are associated with CYP2A6 genetic variants, body mass index, and age. Clin Pharmacol Ther 201 I;90:693-700.

Grinspon RP, Andreone L, Bedecarrás P, Ropelato MG, Rey RA, Campo SM, Bergadá I. Male central precocious puberty: serum profile of anti-Müllerian hormone and inhibin B before, during, and after treatment with GnRH analogue. Int J Endocrinol 2013;2013: 823064.

Grinspon RP, Urrutia M, Rey RA. Male central hypogonadism in paediatrics - the relevance of follicle-stimulating hormone and Sertoli cell markers. Eur Endocrinol 20 I8; 14:67-7|.

Hannema SE, Sävendahl L. The evaluation and management of tall stature. Horm Res Paediatr 2016;85:347-352.

Hendriks AEJ, Drop SLS, Laven JSE, Boot AM. Fertility of tall girls treated with high-dose estrogen, a dose-response relationship. J Clin Endocrinol Metab 2012;97:3107-31।4.

Hero M, Norjavaara E, Dunkel L. Inhibition of estrogen biosynthesis with a potent aromatase inhibitor increases predicted adult height in boys with idiopathic short stature: a randomized controlled trial. J Clin Endocrinol Metab 2005;90:6396-6402.

Hero M, Tommiska J, Vaaralahti K, Laitinen E-M, Sipilä I, Puhakka L, Dunkel L, Raivio T. Circulating antimüllerian hormone levels in boys decline during early puberty and correlate with inhibin B. Fertil Steril 2012;97:1242-1247.

Jensen TK, Finne KF, Skakkebæk NE, Andersson A-M, Olesen IA, Joensen UN, Bang AK, Nordkap L, Priskorn L, Krause $M$ et al. Self-reported onset of puberty and subsequent semen quality and reproductive hormones in healthy young men. Hum Reprod 2016;3 I: |886-1894.

Johnson L, Zane RS, Petty CS, Neaves WB. Quantification of the human Sertoli cell population: its distribution, relation to germ cell numbers, and age-related decline. Biol Reprod 1984;3 I: 785-795.

Jørgensen N, Liu F, Andersson A-M, Vierula M, Irvine DS, Auger J, Brazil CK, Drobnis EZ, Jensen TK, Jouannet $P$ et al. Serum inhibin$b$ in fertile men is strongly correlated with low but not high sperm counts: a coordinated study of 1,797 European and US men. Fertil Steril 2010;94:2128-2134.

Kohva E, Huopio H, Hero M, Miettinen PJ, Vaaralahti K, Sidoroff V, Toppari J, Raivio T. Recombinant human FSH treatment outcomes in five boys with severe congenital hypogonadotropic hypogonadism. J Endocr Soc 20 18;2: I345-1356.

Leschek EW, Flor AC, Bryant JC, Jones JV, Barnes KM, Cutler GB. Effect of antiandrogen, aromatase inhibitor, and gonadotropinreleasing hormone analog on adult height in familial male precocious puberty. J Pediatr 2017;190:229-235.

Lukas-Croisier C, Lasala C, Nicaud J, Bedecarrás P, Kumar TR, Dutertre M, Matzuk MM, Picard J-Y, Josso N, Rey R. Folliclestimulating hormone increases testicular anti-Mullerian hormone $(\mathrm{AMH})$ production through Sertoli cell proliferation and a nonclassical cyclic adenosine 5'-monophosphate-mediated activation of the AMH gene. Mol Endocrinol 2003; I 7:550-56I.

Mauras N, Bell J, Snow BG, Winslow KL. Sperm analysis in growth hormone-deficient adolescents previously treated with an aromatase inhibitor: comparison with normal controls. Fertil Steril 2005;84:239-242.

Mauras N, Gonzalez de Pijem L, Hsiang HY, Desrosiers P, Rapaport R, Schwartz ID, Klein KO, Singh RJ, Miyamoto A, Bishop K. Anastrozole increases predicted adult height of short adolescent males treated with growth hormone: a randomized, placebo-controlled, multicenter trial for one to three years. J Clin Endocrinol Metab 2008;93:823-831.

Mauras N, Ross JL, Gagliardi P, Yu YM, Hossain J, Permuy J, Damaso L, Merinbaum D, Singh RJ, Gaete $X$ et al. Randomized trial of aromatase inhibitors, growth hormone, or combination in pubertal boys with idiopathic, short stature. J Clin Endocrinol Metab 2016; I 0 I:4984-4993.

Orth JM, Gunsalus GL, Lamperti AA. Evidence from Sertoli celldepleted rats indicates that spermatid number in adults depends on numbers of Sertoli cells produced during perinatal development. Endocrinology 1988; I 22:787-794.

Palmert MR, Dunkel L. Clinical practice. Delayed puberty. N Engl J Med 20I2;366:443-453.

Rey R. Endocrine, paracrine and cellular regulation of postnatal antimüllerian hormone secretion by Sertoli cells. Trends Endocrinol Metab 1998;9:27|-276.

Rosenfeld RG, Northcraft GB, Hintz RL. A prospective, randomized study of testosterone treatment of constitutional delay of growth and development in male adolescents. Pediatrics 1982;69:681-687.

Sansone A, Kliesch S, Isidori AM, Schlatt S. AMH and INSL3 in testicular and extragonadal pathophysiology: what do we know? Andrology 2019;7:131-138.

Sharpe RM, McKinnell C, Kivlin C, Fisher JS. Proliferation and functional maturation of Sertoli cells, and their relevance to 
disorders of testis function in adulthood. Reproduction 2003; I 25: 769-784.

Soliman AT, Khadir MM, Asfour M. Testosterone treatment in adolescent boys with constitutional delay of growth and development. Metab Clin Exp 1995;44:1013-1015.

Tanii H, Shitara Y, Horie T. Population pharmacokinetic analysis of letrozole in Japanese postmenopausal women. Eur J Clin Pharmacol 201।;67:1017-1025.

Varimo T, Huopio H, Kariola L, Tenhola S, Voutilainen R, Toppari J, Toiviainen-Salo S, Hämäläinen E, Pulkkinen M-A, Lääperi $M$ et al. Letrozole versus testosterone for promotion of endogenous puberty in boys with constitutional delay of growth and puberty: a randomised controlled phase 3 trial. Lancet Child Adolesc Health 2019;3:109-120.

Venn A, Bruinsma F, Werther G, Pyett P, Baird D, Jones P, Rayner J, Lumley J. Oestrogen treatment to reduce the adult height of tall girls: long-term effects on fertility. Lancet 2004;364:1513-1518.
Wickman S, Sipilä I, Ankarberg-Lindgren C, Norjavaara E, Dunkel L. A specific aromatase inhibitor and potential increase in adult height in boys with delayed puberty: a randomised controlled trial. Lancet 200।;357: 1743-1748.

Wit JM, Hero M, Nunez SB. Aromatase inhibitors in pediatrics. Nat Rev Endocrinol 201।;8: 135-147.

Young J, Chanson P, Salenave S, Noël M, Brailly S, O'Flaherty M, Schaison G, Rey R. Testicular anti-mullerian hormone secretion is stimulated by recombinant human FSH in patients with congenital hypogonadotropic hypogonadism. J Clin Endocrinol Metab 2005;90: 724-728.

Young J, Rey R, Couzinet B, Chanson P, Josso N, Schaison G. Antimüllerian hormone in patients with hypogonadotropic hypogonadism. J Clin Endocrinol Metab 1999;84:2696-2699.

Young J, Rey R, Schaison G, Chanson P. Hypogonadotropic hypogonadism as a model of post-natal testicular anti-Müllerian hormone secretion in humans. Mol Cell Endocrinol 2003;2 I I:5 I-54. 